\title{
Differentiation of First- and Second-Set Grafts of Embryonic, Neonatal and Adult Testis Implanted Beneath the Kidney Capsule of Adult Rat Hosts'
}

\author{
JEANNE HOLDEN LARKIN ${ }^{2}$ \\ Department of Zoology, The University of Michigan, Ann Arbor
}

Although the success of grafts from one individual (donor) to another (host) is affected by many variables (e.g., types of tissue grafted, site of transplantation, relative age and degree of relationship of donor and host, and previous exposure of host to similar grafts), it is generally recognized that grafts between individuals do not take except in the case of identical twins. Grafting between more distantly related individuals usually results in a host reaction leading to resorption or sloughing of the graft.

Medawar ('43) and Rogers ('50) have reviewed the various hypotheses set forward to explain the frequent failure of grafts. Of these hypotheses Schöne's ('12) original view, later promulgated by Medawar ('48, '52), is most favored by the existing evidence. This hypothesis suggests that the resistance of a host to a graft might be due to an antigen-antibody relationship which would bring about a state of actively acquired immunity. According to this concept a given individual has proteins which no other individual shares. Any other proteins whether alone or contained within an individual are foreign to that individual. When a graft is transplanted, the host will develop antibodies against the foreign proteins or antigens contained in the transplanted tissue.

Experiments employing second-set grafts, i.e., a first graft followed by a second graft made at a later time, have provided one of the major lines of evidence for this theory; for while a first graft will slough in a given period of time, a second graft will slough in a much shorter period of time. This reaction is explained by the fact that while antibodies must be built up against the first graft, they will have reached a sufficiently high titer at the time of the second graft to bring about a more rapid destruction of the second graft. The more rapid sloughing of the second grafts is known as the second-set response. Most of the work on the response of second-set grafts has been done with skin (Holman, '24; Gibson and Medawar, '43; Medawar, '44; Sparrow, '53), cornea (Maumenee, '51; Billingham and Boswell, '53), kidney (Simonsen, '55), and tumor tissues (Toolan, '55) transplanted cutaneously, subcutaneously, or intramuscularly. While the phenomenon of actively acquired immunity can readily explain the second-set response, an immune reaction cannot always be demonstrated in grafting experiments. Sometimes unknown factors operate to prevent the normal immune reaction. Billingham, Brent, and Medawar ('56a) have proposed that there are three levels on which an immunological reaction can be prevented from exercising its effect: afferent, central, and efferent.

Afferent inhibition, according to these authors, "is one which takes effect by a direct inactivation of antigens, or by preventing their release from a graft, or their access to a seat of response." An example of this type of inhibition is the phenomenon of enhancement (Kaliss, '55). Here, an incomplete antigenic stimulus is coupled with a fully complete and competent immune system.

\footnotetext{
1 Based on a dissertation submitted in partial fulfillment of the requirement for the degree of Doctor of Philosophy in The University of Michigan, 1958.

${ }^{2}$ Present address: Department of Zoology, Duke University, Durham, North Carolina.
} 
Central inhibition is one which "affects the actual machinery of antibody formation or of some equivalent immunological process." This type of prevention is responsible for the phenomenon of actively acquired tolerance wherein a first dose of complete antigen is placed in an embryo with an undeveloped antibody system (Billingham, Brent, and Medawar, '53). Subsequent grafting at a later time (after birth) results in the toleration of the graft. Radiation also produces this type of inhibition (Benjamin and Sluka, '08).

Efferent inhibition prevents the "effectors of the immune reaction from exercising their action." It is possible that an example of this type of inhibition may be the immunoparalysis described by Felton ('49). He found that by giving mice large injections of type-specific pneumococcal polysaccharides he could impair the immunity of the host.

From the above it is apparent that although the mechanisms of inhibition may vary, the outward end-result in a secondset graft would be the same, namely, tolerance, as demonstrated by the retention of the foreign tissue. With these observations in mind it was decided to test more thoroughly the second-set response of grafts in mammals when the age of the donor tissue was varied while the age of the host was kept constant (adult). In this way one would be dealing with a complete antibody system responding to a varied antigenic stimulus. In these experiments testis tissue was implanted beneath the kidney capsule of adult rat hosts. Pieces of adult, neonatal, or embryonic testes were transplanted beneath an adult kidney capsule and their growth and differentiation studied histologically for the ensuing 8 weeks. A second phase of the investigation compared first- and second-set grafts of testes tissue of different ages in an attempt to evaluate any differences in host response which might exist.

\section{MATERIALS AND METHODS}

Albino rats were chosen for the experiments because they are relatively easy to handle and care for and because they are resistant to most infections. In experiments of this type it is usually considered desirable to use animals of an inbred strain. However, since an inbred strain was not available, animals of the widest genetic diversity were used. In this manner one is better able to gain constancy of results (Billingham, '57).

The kidney capsule was chosen as the host site because it was known to be favorable for the growth of transplanted gonads (Buyse, '33, '35). The testis was chosen as the donor tissue because it was known to differentiate well in foreign environments (Moore, '26). Since Macintyre ('56) reported that there was no indication of any correlation between the sex of the host and the takes of the grafts, males were used throughout the experiments.

Adult donor tissue was obtained by anesthetizing the animal with ether, opening the scrotal sac and excising a small piece of the testis. Testes from the neonatal and embryonic donors were recovered from the abdominal cavity. The tissue or organ was placed in a sterile Petri dish containing sterile Kreb's Ringer solution including phosphate. With iridectomy scissors all donor tissue was then cut up into smaller pieces. For the adult donor tissue one seminiferous tubule approximately $0.5 \mathrm{~mm}$ long was used. Both neonatal and embryonic testes were cut in half so that one testis provided two pieces of donor tissue.

The host animal was anesthetized with ether and its kidney was brought to the surface by means of a metal loop with a handle. Then the grafts were implanted beneath the kidney capsule by means of a small pipette. Finally, the kidney was returned to the abdominal cavity and the incision was closed.

At autopsy the grafts were removed together with adjacent kidney tissue and placed in Bouin's fixative solution containing $1 \%$ urea. The tissue was then dehydrated, cleared, and embedded in paraffin ("Tissuemat"). The material was serially sectioned at 6 microns and subsequently stained with Heidenhain's azan triple stain.

\section{RESULTS}

The first phase of the investigation was to determine the fate of single grafts of testicular tissue from adult, newborn, and fetal rats after implantation beneath the kidney capsules of adult hosts. Description 
of the tissues of the grafts after periods of $2,4,6$, and 8 weeks in transplant forms part I of this report. Part II deals with the second phase of the investigation, in which the fate of both first and second grafts was determined after implantation into adult hosts at intervals of two weeks. In these experiments the first graft was implanted beneath the capsule of the left kidney on day zero. Two weeks later the right kidney also received a subcapsular graft. After two more weeks the animals were autopsied and both grafts recovered, if possible. It is evident that the first grafts were 4 weeks old when obtained, while the second grafts were but two weeks old.

Table 1 summarizes the experiments performed in both phases of the investigation.

Fate of single implants

\section{Grafts of adult testis}

Only two single implants of adult testis were recovered (one each from the 4- and 8 -week series) as recognizable seminifer- ous tubules. These tubules were oriented tangentially to the kidney and within the capsule. The tubules consisted mainly of scattered Jightly staining degenerate epithelial cells (fig. 1). The lumina were occluded.

The remaining recoveries consisted of identifiable graft sites, at which extensive proliferation of the connective tissue of the renal capsule was abserved. This proliferated tissue was completely external to the tubular portion of the renal cortex in all but three instances. In the latter the graft sites showed an abundant penetration of connective tissue into the interior of the kidney cortex. At the graft site of one 4-week implant the tissue of the kidney in the vicinity of the proliferated capsular mass was somewhat modified. Cords of cells present there might be the primordia of new uriniferous tubules. Possibly they stemmed from collecting ducts but their origin could not be determined with cer tainty. Finally, in one graft site of the 8-week series renal tubules surrounded by

TABLE 1

Summary of experiments

\begin{tabular}{|c|c|c|c|c|c|c|c|}
\hline \multicolumn{2}{|c|}{$\begin{array}{l}\text { Age of testis tissue } \\
\text { at time of implantation }\end{array}$} & \multicolumn{2}{|c|}{$\begin{array}{l}\text { Weeks in } \\
\text { transplant }\end{array}$} & \multicolumn{2}{|c|}{$\begin{array}{c}\text { Number } \\
\text { grafted }\end{array}$} & \multicolumn{2}{|c|}{$\begin{array}{l}\text { Number } \\
\text { recovered }\end{array}$} \\
\hline \multicolumn{8}{|c|}{ Part I--single implants } \\
\hline \multirow{2}{*}{\multicolumn{2}{|c|}{$\begin{array}{l}\text { Adult (over } 6 \text { months old) } \\
\text { Adult }\end{array}$}} & \multicolumn{2}{|c|}{2} & \multicolumn{2}{|c|}{5} & \multicolumn{2}{|c|}{2} \\
\hline & & \multirow{2}{*}{\multicolumn{2}{|c|}{4}} & \multicolumn{2}{|c|}{5} & \multicolumn{2}{|c|}{5} \\
\hline Adult & & & & \multirow{2}{*}{\multicolumn{2}{|c|}{$\begin{array}{l}5 \\
5\end{array}$}} & \multirow{2}{*}{\multicolumn{2}{|c|}{$\begin{array}{l}1 \\
2\end{array}$}} \\
\hline Adult & & \multicolumn{2}{|c|}{$\begin{array}{l}b \\
8\end{array}$} & & & & \\
\hline NeonataI ( 4 & ld) & \multicolumn{2}{|c|}{2} & \multicolumn{2}{|c|}{5} & \multicolumn{2}{|c|}{5} \\
\hline Neonatal & & \multirow{2}{*}{\multicolumn{2}{|c|}{$\begin{array}{l}4 \\
6\end{array}$}} & \multicolumn{2}{|c|}{5} & \multicolumn{2}{|c|}{4} \\
\hline Neonatal & & & & \multicolumn{2}{|c|}{5} & \multicolumn{2}{|c|}{5} \\
\hline Neonatal & & \multicolumn{2}{|c|}{8} & & & & \\
\hline Neonatal & & \multicolumn{2}{|c|}{29} & \multicolumn{2}{|c|}{1} & \multicolumn{2}{|c|}{1} \\
\hline Embryonic & fetus) & \multicolumn{2}{|c|}{2} & \multicolumn{2}{|c|}{5} & \multicolumn{2}{|c|}{5} \\
\hline Embryonic & & \multirow{2}{*}{\multicolumn{2}{|c|}{$\begin{array}{l}4 \\
6\end{array}$}} & \multicolumn{2}{|c|}{5} & \multicolumn{2}{|c|}{4} \\
\hline Embryonic & & & & & & & \\
\hline Embryonic & & & & & & & \\
\hline $\begin{array}{c}\text { First } \\
\text { implant }\end{array}$ & $\begin{array}{l}\text { Second } \\
\text { implant }\end{array}$ & 1 st & 2nd & $1 \mathrm{st}$ & 2nd & 1st & $2 n d$ \\
\hline Part II-double & nts & & & & & & \\
\hline Adult & Adult & 4 & 2 & 10 & 10 & 8 & 7 \\
\hline Adult & Neonatal & 4 & 2 & 10 & 10 & 4 & 9 \\
\hline Adult & Embryonic & 4 & 2 & 10 & 10 & 4 & 9 \\
\hline Embryonic & Adult & 4 & 2 & 10 & 10 & 8 & 5 \\
\hline Embryonic & Neonatal & 4 & 2 & 10 & 10 & 10 & 10 \\
\hline Embryonic & Embryonic & 4 & 2 & 10 & 10 & 9 & 10 \\
\hline Neonatal & NeonataI & 4 & 2 & 10 & 10 & 4 & 3 \\
\hline
\end{tabular}


a proliferated mass of capsular connective tissue showed degeneration. The cells of these renal tubules had separated from the basement membranes and sloughed into the lumina. Marked cytolysis was noted.

\section{Grafts of neonatal testis}

Proliferation of cells had occurred by two weeks resulting in the presence of three to 5 cell layers which surrounded a newly formed lumen. Although primary spermatocytes had differentiated, their nuclei and those of some of the spermatogonia were markedly pycnotic (figs. 2 and 3 ). Fragmentation of cell nuclei and sloughing of single cells and multinucleate masses into the lumina of tubules were observed. It would seem then that the grafts had undergone early phases of growth and differentiation. By two weeks however, degenerative changes had already set in.

A study of 4-week implants revealed a decrease in the epithelial layers of the seminiferous tubules so that only two or three rows of cells remained. Only occasionally were primary spermatocytes found. Few pycnotic, or fragmented cells were present. Apparently the pycnotic, fragmented, and dissolving cells that were so prevalent in the two-week stage of development of the grafts and been resorbed by 4 weeks.

Fewer tubules were present in the 6week series and only one or occasionally two layers of epithelial cells were present. The cells composing these layers were spermatogonia and a few scattered Sertoli cells. Some of the cells were pycnotic and on occasion were found in the lumen of a tubule. Apparently destructive alterations resulting in the sloughing and resorption of degenerated cells had reached a maximum at 6 weeks.

There was some indication that by 8 weeks a new wave of proliferation and accompanying degeneration of differentiating cells was again in progress. In two grafts tubules consisted of two to 4 rows of epithelial cells which were chiefly spermatogonia, but an occasional primary spermatocyte could be recognized. Cells toward the periphery of the tubule appeared healthy, and mitotic divisions were seen in several instances (fig. 4). Near the lumen the cells exhibited varying degrees of pycnosis, fragmentation, and dissolution.

One implant of neonatal testis was allowed to persist in the host for more than 6 months. Tubules of this 29-week implant contained one to three rows of cells, including only spermatogonia and Sertoli cells. Some cells were healthy; others were pycnotic (fig. 5) or fragmented. Compatibility between graft and host must have been good to allow survival for this lengthy period. This experiment suggests that grafts of the newborn testis to adult hosts may persist indefinitely.

\section{Grafts of embryonic testis}

After two weeks single implants of embryonic testis were healthy and had developed a good vascular supply. Mitotic divisions in the grafted tissue indicated that the grafts were actively growing. Since no primary spermatocytes were found, differentiation apparently had not yet begun. By 4 weeks, however, these embryonic implants exhibited both differentiation of spermatocytes and cellular pycnosis. Destructive changes, though present, were not as marked as in the 4-week neonatal implants. The majority of the tubules of the 6-week implants contained only two or three epithelial layers. Pycnotic cells and isolated groups of cells were common in the lumina of the tubules. Apparently grafts grew and differentiated well for a time. Then the primary spermatocytes and the layers of spermatogonia in turn became degenerate and were sloughed into the lumen. This sloughing of cellular debris into the lumen which began at 4 weeks reached its peak at 6 weeks. By 8 weeks tubules again contained primary spermatocytes and cells in mitosis. There were more cell layers present and fewer degenerating cells in the lumina (fig. 6) than were observed in the 6-week grafts. These grafts, similar to the neonatal implants at 8 weeks, suggest that a new wave of proliferation and accompanying degeneration had occurred.

\section{Fate of double implants}

Grafts of the adult-adult, adult-neonatal, adult-embryonic series

1. First implants: adult. Regardless of whether the second implant was adult, neo- 
natal, or embryonic testis tissue, first adult implants in all three experimental groups were similar to 4-week single implants of adult tissue. In sections all graft sites showed remnants of seminiferous tubules whose epithelial cells were all degenerating (fig. 7). Cells were few in number and frequently fragmented. Lumina of the tubules were occluded with cellular debris. In addition, connective tissue from the capsule had proliferated extensively at many of the graft sites. Although these first implants were similar to single implants of the same age, variations were observed in the second implants.

2. Second implant: adult. When the second implant was adult tissue, it was observed that, in at least two cases, breakdown of renal tubular tissue had resulted from the extensive invasion of the connective tissue. This same degeneration was not noted until 8 weeks in the single implants of adult tissue. The fact that this reaction occurred in the present series after only two weeks may indicate an increased host reaction against a second implant of adult testis. Increased support for this hypothesis is the finding that there were fewer cells in the degenerating seminiferous tubules, when present, than there were in the 4-week single implants of adult testis.

3. Second implant: neonatal. Second implants of neonatal tissue differed significantly from the two-week single implants of newborn testis. In general, the second grafts were retarded in rate of growth and differentiation of spermatocytes as compared with single implants. Not only were there fewer cells in the tubules, but also there were fewer degenerating cells (fig. 8). Second implants apparently became well established, but their growth and differentiation were evidently slower than in single implants. This evidence for retardation of second grafts is interpreted to mean that the host environment was somehow altered by the presence of the first graft. The possible nature of this alteration will be considered in the discussion.

4. Second implant: embryonic. Second implants of embryonic tissue did not differ appreciably from the two-week single implants of embryonic testis. The typical implant contained tubules with approximately three rows of epithelial cells (fig. 9). Only spermatogonia and Sertoli cells were present and mitosis was common. These grafts were in a very healthy condition. In contrast to the development of second implants of neonatal testis, therefore, there was no evidence that second implants of embryonic testis develop differently from first implants.

\section{Grafts of the embryonic-adult, embryonic- neonatal, and embryonic-embryonic series}

1. First implants: embryonic. Regardless of whether the second implant was adult, embryonic, or neonatal, first embryonic implants in all three experimental groups were similar to the 4-week single implants of embryonic testis. Tubules showed that both growth and differentiation of primary spermatocytes had occurred. Degenerative changes were obvious. Cells with pycnotic and fragmenting nuclei, and cells exhibiting karyolysis were common in the tubules. Although these first implants were similar to single implants of the same age, variations were observed in the second implants.

2. Second implant: adult. The twoweek tubule remnants in this experiment were generally similar to those of the 4week single implants of adult testis. Tubules consisted of only a few isolated epithelial cells and, in one instance, mostly of cells which had originated from the connective tissue and which surrounded the few remaining epithelial cells. This would indicate that the host reaction to a second implant of adult tissue was affected by a previous implant.

3. Second implant: neonatal. Second implants of neonatal tissue were considerably retarded in comparison with the twoweek single implants of newborn testis. It will be recalled that tubules of single neonatal implants showed that while both growth and differentiation had occurred, great numbers of degenerating cells were present. By contrast, the tubules of second implants in this series presented little evidence of differentiation although some primary spermatocytes were present. Pycnosis, however, was not as marked as in the single implants. This evidence for re- 
tardation of second grafts is similar to that noted in the experiments where a first implant of adult tissue was followed by a second graft of neonatal testis. These results are interpreted to mean that the first graft in some manner altered the host environment.

4. Second implant: embryonic. Second implants of embryonic testis were similar to the single implants of embryonic tissue. It will be recalled that the single embryonic implants were recovered in healthy condition. The typical graft exhibited much growth but neither differentiation of spermatocytes nor degeneration had occurred. Grafts in this series appeared therefore to have been unaffected by the presence of a first implant of embryonic tissue. This result is similar to the experiment in which a second embryonic implant was unaffected by the presence of a first adult implant.

\section{Grafts of the neonatal-neonatal series}

1. First implant: neonatal. These implants did not differ significantly from the 4-week single implants of neonatal testis. In general, growth of the cells of the seminiferous tubules had ceased and differentiation was curtailed. There was a decrease in the number of intact nuclei due to degeneration and fragmentation of cells.

2. Second implant: neonatal. Second implants of neonatal tissue differed from the two-week single implants of tissue of this age in that they were retarded in both growth and differentiation. There was only a negligible indication of degeneration. The retardation in growth and development is interpreted to mean that the host enviroment had been altered by the presence of the first graft in such a manner as to inhibit the second. These results are comparable to those obtained when a second neonatal implant was preceded by a first adult graft and by a first embryonic graft.

\section{DISCUSSION \\ Growth of single implants}

There is good evidence from the results of these experiments with both first and second grafts that the host could react to limit the growth and spermatogenesis of grafted testicular tissue of any age. Al- though host antibodies may have been produced in response to the grafts, the temperature of the body cavity must be considered a factor inimical to maintenance or continued differentiation of maturation stages in the seminiferous tubules of testes grafted to the kidney. Taking into consideration all the factors known to affect the growth of grafted tissue, one is nevertheless impressed by the observation that implanted testis will persist for many months as shown here and previously by Moore ('19, '26) and Williams ('50). It appears that the testis differs from homografts of some tissues which are resorbed or sloughed in a relatively short time after grafting. Similarly, Harris and Eakin ('49) have shown that subcutaneously transplanted pieces of adult rat ovary will persist and function for some time. On the other hand, homoplastic skin grafts commonly persist only a relatively short time (Medawar, '44, '45).

It is possible that under the conditions of this experiment the testis is less antigenic than more sensitive tissues or perhaps that the testis is simply less sensitive to host antibodies than are those tissues which persist for a shorter time.

\section{Grafts of adult testis}

The adult implants which were recovered in the present series contained no spermatogenic cells in the later stages of differentiation. The spermatogonia present were degenerate and the seminiferous tubules were collapsed, suggesting that the spermatogenic cells were affected by an antagonistic reaction on the part of the host. The degeneration of renal tubules noted in two instances (8-week single adult implants and the second adult graft in the adult-adult series ) may indicate that the disintegration products of the degenerating graft affected the kidney adversely, probably in an indirect manner through stimulation of connective tissue proliferation in the host. Similar evidence has been presented by Rivers, Sprunt, and Berry ('33) and Dempster ('53a, '53b) who mention cases where the host tissue was affected by the graft.

\section{Grafts of neonatal testis}

After two weeks single neonatal implants exhibited a slackening of both 
growth and differentiation; in addition, degenerative changes were obvious. These destructive alterations continued throughout the next two weeks and seemed to reach a maximum at 6 weeks. By 8 weeks, however, some implants provided evidence of a new wave of proliferation and accompanying degeneration of differentiating cells. Thus, the neonatal implants survived better than the adult grafts during the time limitations of these experiments.

The possible explanations for the initial success of implants of neonatal tissue should be examined more closely. Loeb ('45) claims that grafts of neonatal endocrine tissue in general have better success in transplantation than do adult implants. Medawar ('45), on the other hand, found that this does not hold true for skin grafts in rabbits. Perhaps the fact that skin is not as directly under endocrine control as some other organs may be a factor which would help account for the divergent results. It is likely that neonatal implants are stimulated to precocious growth when subjected to the influence of adult gonadotropic hormones. Loeb also suggested that younger tissues succeed better because they are growing very actively.

The proliferative and degenerative cycles sometimes seen in the 8-week implants might be explained as follows. While the graft of newborn testis is undergoing growth and differentiation, its antigens are being released into the host system. The host in turn responds to these foreign proteins by the production of antibodies. When the latter then enter into union with the antigens, degenerative changes in the graft result, releasing consequently greater quantities of antigen. It follows then that the titer of circulating antibody in the host animal would be drastically reduced. This subsequent drop in antibody level then may permit the remaining spermatogonia to grow and to begin their differentiation. The advent of new and differentiated cells provides more antigen which in turn evokes the production of more antibodies. Thus a cycling of proliferation and degeneration might occur, which could indicate that a state of "compromise compatibility" between graft and host had been achieved such that the graft was no longer in danger of being completely eliminated. Support for such an explanation is found in the fact that one neonatal testis persisted in a relatively healthy condition for more than 6 months.

\section{Grafts of embryonic testis}

Embryonic implants exhibited growth and development up to 4 weeks after implantation when degeneration became apparent. At no time, however, were any stages later than primary spermatocytes found in these grafts, although normal testes give rise to secondary spermatocytes and spermatids at the same relative age. This result seems to indicate that secondary spermatocyte and spermatid production in homografts of testicular tissue is at least in part inhibited by the higher body cavity temperature of the host environment. Nevertheless, the later discussion of neonatal second-set grafts will provide evidence for another factor which influences the degeneration of these young implanted tissues, namely, an immune reaction.

Following the lessening or cessation of developmental processes at 4 weeks in these grafts, growth and concomitant degeneration of spermatogonia were again observed at 8 weeks. These observations would seem to indicate that spermatogonial proliferation may continue for some time under these conditions. Finally, however, all cells thus formed are eventually destroyed (Moore, '26). Thus, these cyclical changes are similar to those noted for the single neonatal implants and can presumably be explained by the same mechanism outlined in that section.

Embryonic tissues may share similar antigens with adult tissues (Cooper, '46, Schechtman, '47). Therefore, at first sight, the healthy state of two-week embryonic grafts contrasts strikingly with the degenerative changes seen in two-week neonatal or adult grafts. Presumably, the embryonic testis tissue, however, has a higher growth potential, hence, it is probable that initially its rate of growth exceeds for a time the host response which is demonstrated in grafts of neonatal or adult tissue. Evidence which suggests that actively growing tissues can to some extent overcome the host reaction comes from re- 
search on tumor tissues (Loeb, '45). Later, however, as the rate of growth of the transplanted embroynic gonads decreased, signs of degeneration were evident. By this stage host antibodies were presumably contributing to the curtailment of growth and differentiation.

\section{Growth of double implants}

The results of the double implant series indicate that after 4 weeks none of the first-set implants in the presence of a second graft differed in any significant way from single grafts recovered after 4 weeks. This observation might have been expected since the literature provides only a few examples which show that a first graft may be modified by the presence of a second (Billingham, Brent, and Medawar, '56b).

The present experiments do give evidence that (1) a second graft may affect the host differently from the first graft, and (2) second grafts of neonatal testis may be affected by first grafts. Second grafts of neonatal tissue, however, were significantly retarded in differentiation whether preceded by adult, embryonic, or neonatal tissues.

\section{Second-set grafts of adult testis}

Where second grafts of adult testis were preceded by grafts of adult tissue, breakdown of renal tubules was detected at two weeks. This reaction was first detected only in the 8-week single series for single implants. These results indicate that a reaction between graft and host occurred more rapidly after second-set grafts than after single implants. Presumably the titer of antibodies in the host was high enough at the time of the second implantation to cause a more rapid graft destruction. As in single implants disintegration products of the graft stimulated the growth of host connective tissue, which in turn could account for the destruction of renal tubules.

Second grafts of adult testis preceded by grafts of embryonic tissue resembled the 4-week single adult implants. It will be remembered, however, that these second adult implants were recovered after only two weeks. These results indicate again that there was a more rapid host immune reaction against a second implant.

\section{Second-set grafts of embryonic testis}

Second grafts of embryonic tissue in the presence of either adult or embryonic firstset grafts, unlike second grafts of adult testis, apparently did not elicit any more of a host immune response than did single grafts of embryonic tissue during the first two weeks. Embryonic tissue appeared to flourish whether in an initial graft or in a second graft; yet is it known to be antigenic. Burke, Sullivan, Petersen, and Weed ('44) report that morphological differentiation occurs before antigenicity arises and that various antigens arise and disappear during the course of development so that at varying times different complexes of antigens may be present. It may further be hypothesized that antigen formation proceeds from the general (rat antigens) to the more specific (rat tissue antigens). Gengozian and Makinodan ('56) have shown, for example, that protected mice recovering from lethal doses of $\mathrm{x}$-irradiation respond immunologically first to distantly related antigens (sheep) and only later to mouse antigens. It is possible that embryonic tissue contains only the general (rat) antigens which at the time of implantation are still completely acceptable to the host. If this is so, it is possible then that under these conditions no antibodies were elicited. Furthermore, even if tissue specific antigens were produced, the quantity present may not have been sufficient to elicit antibody formation.

Finally, the rapid growth of embryonic tissue may enable it to overcome initially the possible retarding influence of a host immune response. A similarity might be drawn at this point to tumor tissue which is also rapidly growing. Indeed, it has been shown by Billingham, Brent, and Medawar ('56a) that a tumor is able to escape immunological control with only a slight remission to immunity. A tumor, due to an increased rate of growth, can frequently overcome host resistance and kill the host. In addition to their similar rapid growth rates, embryonic and tumor tissues share at least three constitutional attributes, namely, morphological, immuno- 
logical, and biochemical as Greene ('51) has pointed out. He concluded that they are dissimilar only in their differentiative capacities.

\section{Second-set grafts of neonatal testis}

Second-set grafts of neonatal testicular tissue present clearcut evidence for a host immune reaction. Regardless of the age of the first donor tissue, second-set grafts of neonatal tissue were always equally inhibited. These results suggest that adult, neonatal, and embryonic tissues share similar antigenic factors. To my knowledge the type of reaction demonstrated here, namely a retardation of differentiation of a second neonatal implant, has not previously been reported.

It is most probable that the observed retardation of growth and differentiation results from an immunological response. If the first graft had somehow produced an inhibition of the immune response, greater tolerance and, hence, more rapid growth and differentiation of the second graft should have ensued. Since all second-set grafts were retarded, however, one can only conclude that an actively acquired immune response of an unusual type was present. An actively acquired immunity should bring about a more rapid destruction of the second graft rather than a retardation of its development. In all experiments where destruction or sloughing of cells was observed the degeneration occurred principally in differentiating cells. Spermatogonia and perhaps Sertoli cells persist after spermatocytes had disappeared. As already noted it is possible that these relatively undifferentiated cells of the testis contain only the more general antigens which are completely acceptable to the host, whereas differentiating spermatocytes contain specific antigens which elicit the formation of host antibodies.

Although temperature of the body cavity is probably a factor in the degeneration of implanted testis tissue, the evidence of second-set grafts indicates that there is also an immune reaction which plays an additional role. As a working hypothesis, it is proposed that antibodies to the protein of differentiating spermatocytes, spermatids, or sperm are produced by a graft of the testis of any of the ages used. Such antibodies might conceivably inhibit the differentiation of those stages of spermatogenesis after spermatogonial stages in second grafts of neonatal gonads and so account for the relatively undifferentiated state of the tubules in this material.

\section{SUMMARY}

1. Homoplastic single implants of adult, neonatal, and embryonic testis were grown beneath the kidney capsule of adult white rats for periods ranging from two weeks to 29 weeks. In addition, both first and second implants were made in the following age combinations: adult-adult, embryonic-adult, adult-embryonic, embryonicembryonic, adult-neonatal, neonatal-neonatal, and embryonic-neonatal.

2. Few single implants of adult testis were recovered as seminiferous tubules. In these the tubules were collapsed and cells had degenerated. In all other recognized graft sites, however, connective tissue proliferation was noted.

3. Single neonatal implants exhibited growth, differentiation, and degeneration at two weeks. Sloughing and resorption of degenerated cells was evident after 4 and 6 weeks. By 8 weeks there was some evidence of a new wave of proliferation and degeneration. A 29-week implant was healthy but its tubules contained only spermatogonia and perhaps Sertoli cells.

4. Single embryonic implants were healthy at two weeks, but exhibited cellular pycnosis at 4 weeks. Sloughing of cellular debris into the lumens of seminferous tubules was apparent at 4 and 6 weeks. By 8 weeks there was evidence that spermatogonia were dividing and differentiating again.

5. In experiments with double implants, first grafts recovered after 4 weeks differed in no significant way from single implants after 4 weeks.

6. Breakdown of renal tubules in the vicinity of the second graft was detected in hosts receiving both first and second implants of adult testis. Since this same breakdown was not detected until 8 weeks after implantation in hosts receiving single adult implants, there is evidence that a second adult graft elicits a stronger host reaction. 
7. There was no evidence that second grafts of embryonic tissue elicited any more of a host response than did single grafts of embryonic tissue. It is proposed that second embryonic grafts were able to overcome the host reaction due to their inherently rapid rate of growth.

8. Second grafts of neonatal tissue were inhibited in development regardless of the age of the first implant (adult, neonatal, or embryonic). All three age groups thus appear to share similar antigens. It is postulated that an active immune reaction accounts for the inhibition of differentiation in the second grafts. It is further hypothesized that antibodies to the proteins which accompany differentiation of spermatocytes account for retardation of cells within the seminiferous tubules in second implants of neonatal testis.

\section{ACKNOWLEDGMENTS}

The author wishes to express her gratitude to Dr. Norman E. Kemp and Dr. Edward C. Horn for their guidance and criticism during the preparation of this manuscript.

\section{LITERATURE CITED}

Benjamin, E., and E. Sluka 1908 Antikörperbildung nach experimenteller schädigung des hämatopoetischen systems durch röntgenstrahlen. Wien. klin. Wchnschr., 21: 311-318.

Billingham, R. E. 1957 Studies on epidermal cell suspensions, with particular reference to problems of transplantation immunity. Ann. N. Y. Acad. Sci., 64: 799-810.

Billingham, R. E., and T. Boswell 1953 Studies on the problem of corneal homografts. Proc. Roy. Soc. London, B, 141: 392-406.

Billingham, R. E., L. Brent and P. B. Medawar 1953 "Actively acquired tolerance" of foreign cells. Nature, 172: 603-606.

__ 1956a "Enhancement" in normal homografts, with a note on its possible mechanism. Transpl. Bull., 3: 84-88.

1956b Quantitative studies on tissue transplantation immunity. III. Actively acquired tolerance. Philos. Trans. Roy. Soc. London, B, 239: 357-414.

Burke, V., N. P. Sullivan, H. Petersen and R. Week 1944 Ontogenetic change in antigenic specificity of the organs of the chick. J. Infect. Dis., 74: 225--233.

Buyse, A. 1933 The transplantation of embryonic mammalian primordia. Anat. Rec., (Suppl.) 55: 10 (abstract).

1935 The differentiation of transplanted mammalian gonad primordia. J. Exp. Zool., 70: 1-41.
Cooper, R. S. 1946 Adult antigens (or specific combining groups) in the egg, embryo, and larva of the frog. J. Exp. Zool., 101: 143-171.

Dempster, W. J. 1953a Kidney homotransplantation. Brit. J. Surg., 40: 447-465.

$1953 \mathrm{~b}$ Modern trends in renal transplantation. In: Modern Trends in Urology. P. B. Hoeber, Inc., Harper and Bros., New York, chap. 15.

Felton, L. D. 1949 The significance of antigen in animal tissues. J. Immunol., 61: 107-117.

Gengozian, N., and T. Makinodan 1956 Immune response studies on lethally X-irradiated mice protected with bone marrow. Rad. Res., 5: 479 (abstract).

Gibson, T., and P. B. Medawar 1943 The fate of skin homografts in man. J. Anat., 77: 299310.

Greene, H. S. N. 1951 A concertion of tumor autonomy based on transplantation studies: A review. Cancer Res., 11: 899-903.

Harris, M., and R. M. Eakin 1949 Survival of transplanted ovaries in rats. J. Exp. Zool., 112; 131-163.

Holman, E. 1924 Protein sensitization in isoskin grafting. Surg. Gyn. Obstet, 38: 100-106.

Kaliss, N. 1955 Reversal of the "second set response" in tumor homotransplantation. Transpl. Bull., 2: 52-53.

Loeb, L. 1945 The Biological Basis of Individuality. Charles C Thomas, Springfield, Illinois.

Macintyre, M. N. 1956 Effect of the testis on ovarian differentiation in heterosexual embry onic rat gonad transplants. Anat. Rec., 124: $27-46$.

Maumenee, A. E. 1951 The influence of donorrecipient sensitization on corneal grafts. Am. J. Ophthalmol., 34: 142-152.

1943 Notes on the problem of skin homografts. Bull. War Med., 4: 1-4.

1944 The behaviour and fate of skin autografts and skin homografts in rabbits. J. Anat., 78: 176-199.

1945 A second study of the behaviour and fate of skin homografts in rabbits. Ibid., 79: $157-176$

1948 Immunity to homologous grafted skin. III. The fate of skin homografts transplanted to the brain, to subcutaneous tissue, and to the anterior chamber of the eye. Brit. J. Exp. Path., 29: 58-69.

1952 A biological analysis of individuality. Am. Sci., 40: 632-639.

Moore, C. R. 1919 On the physiological properties of the gonads as controllers of somatic and psychical characteristics. I. The rat. J. Exp. Zool., 28: 137-160.

1926 On the properties of the gonads as controllers of somatic and psychical characteristics. IX. Testis graft reactions in different environments (rat). Am. J. Anat., 37: 351416.

Rivers, T. M., D. H. Sprunt and G. P. Berry 1933 Observations on attempts to produce acute disseminated encephalomyelitis in monkeys. J. Exp. Med., 58: 38-53.

Rogers, B. O. 1950 The problem of skin homografts. Plastic Reconstr. Surg., 5: 269-282. 
Schechtman, A. M. 1947 Antigens of early developmental stages of the chick. J. Exp. Zool, 105: 329-348.

Schöne, G. 1912 Die heteroplastische und homoplastische Transplantation. J. Springer, Berlin.

Simonsen, M. 1955 The acquired immunity concept in kidney homotransplantation. Ann. N. Y. Acad. Sci., 59: 448-452.

Sparrow, E. M. 1953 The behaviour of skin autografts and skin homografts in the guinea- pig with special reference to the effect of cortisone acetate and ascorbic acid on the homograft reaction. J. Endocrin., 9: 101-113. Toolan, H. W. 1955 The possible role of cortisone in overcoming resistance to the growth of human tissues in heterologous hosts. Ann. N. Y. Acad. Sci., 59: 394-400.

Williams, R. G. 1950 Studies of living interstitial cells and pieces of seminiferous tubules in autogenous grafts of testis. Am. J. Anat., 86: $343-370$. 
PLATE 1

EXPLANATION OF FIGURES

1 Remnant of seminiferous tubule from 4-week implant of adult testis. Tubule is entirely within the kidney capsule (upper right). Renal tubules at lower margin of photograph. $\times 480$.

2 Section through two-week implant of neonatal testis showing spermatogonia and differentiated but pycnotic primary spermatocytes. $\times 480$.

3 Section through same two-week implant of neonatal testis as figure 2 but in another area showing marked pycnosis of spermatogonial cells toward the lumen (bottom of photograph). $\times 480$.

4 Section through 8-week implant of neonatal testis. Two rows of cells including Sertoli cells and spermatogonia are present but no later stages of differentiation are observed. Note mitotic figures at lower margin of photograph. $\times 480$.

5 Section through 29-week neonatal implant. One to three rows of cells, including some pycnotic spermatogonia are present. $\times 480$. 

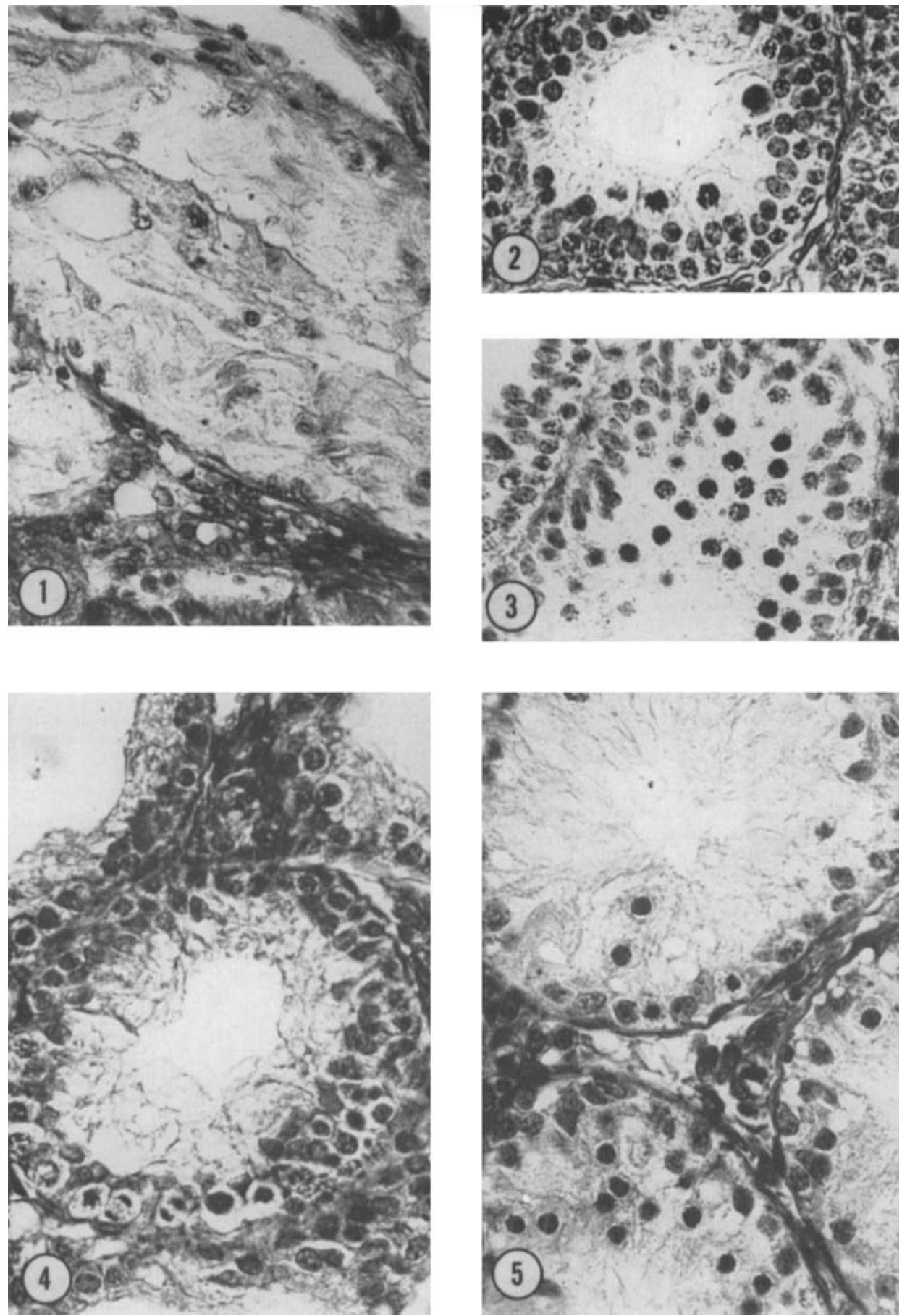


\section{PLATE 2}

EXPLANATION OF FIGURES

6 Eight-week implant of embryonic testis. Healthy cells occupy the periphery of the tubules, but some degenerating cells occur toward the Iumina. Note primary spermatocyte at upper right of photograph. $\times 480$.

7 Remnant of seminiferous tubule of first adult implant in the adult-embryonic series. The Jumen is occluded and epithelial cells are degenerating. Kidney capsule above and renal tubules below, $\times 480$.

8 Section through second neonatal implant in the adult-neonatal series. Tubules are composed of two to three rows of healthy cells. No primary spermatocytes are observed and the lumina are not formed as yet. $\times 480$.

9 Section of second embryonic implant in the adult-embryonic series. Note two or three rows of healthy cells in seminiferous tubules and absence of primary spermatocytes. No lumina are present. $\times 480$. 

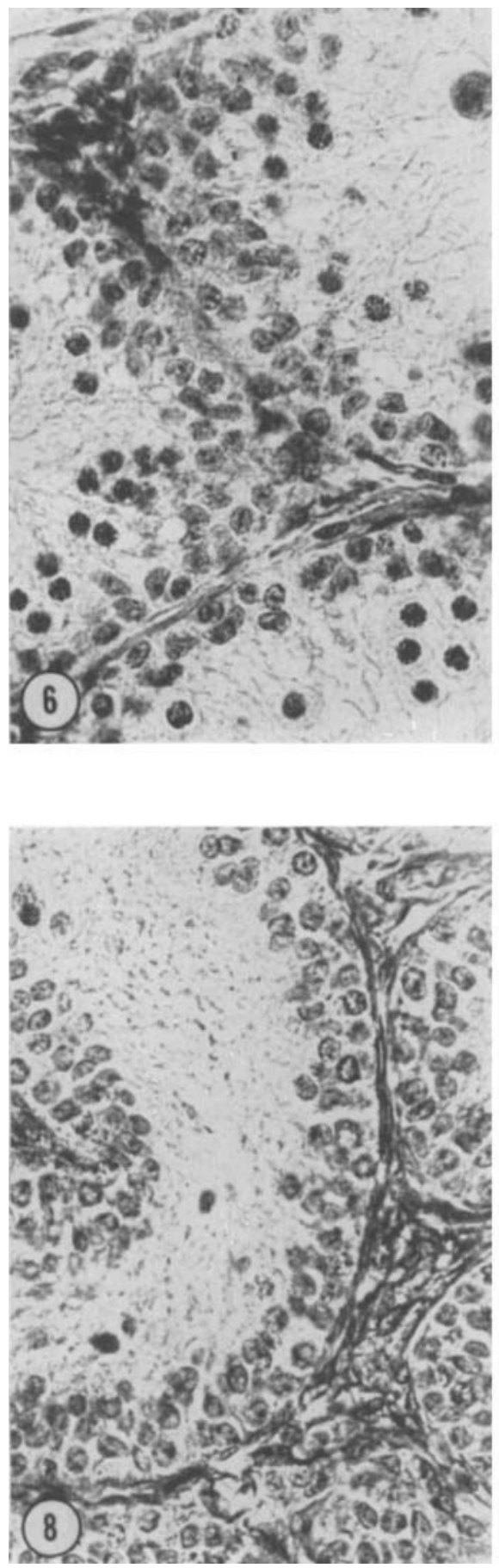
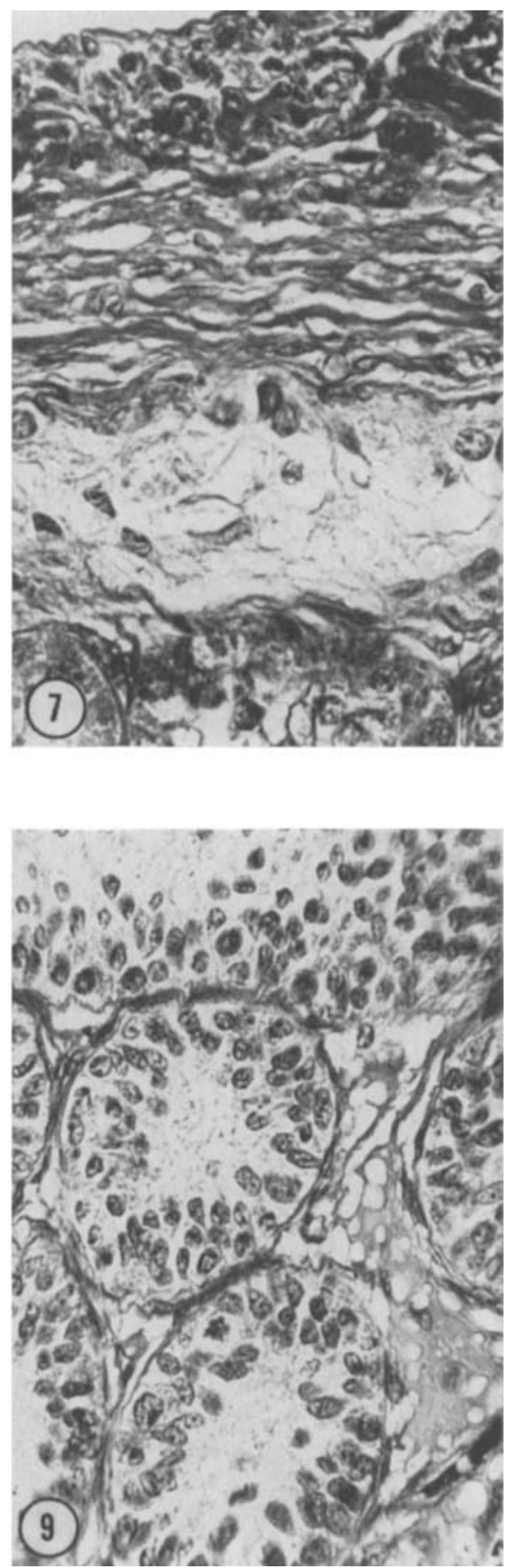